Research Article

\title{
Study on Shear Strength Characteristics of Marine Silt Modified by Steel Slag
}

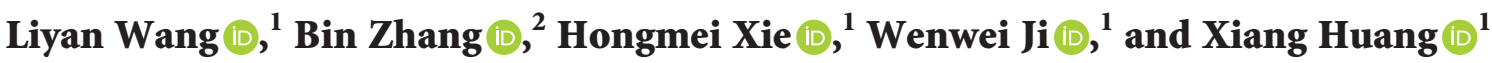 \\ ${ }^{1}$ Jiangsu Province Engineering Research Center of Geoenvironmental Disaster Prevention and Remediation, \\ Jiangsu University of Science and Technology, No. 666 Changhui Road, Zhenjiang, Jiangsu Province, China \\ ${ }^{2}$ Jiangsu Surveying and Design Institute of Water Resources Co., Ltd., Yangzhou, Jiangsu Province, China \\ Correspondence should be addressed to Liyan Wang; wly_yzu@163.com
}

Received 29 June 2021; Accepted 7 August 2021; Published 18 August 2021

Academic Editor: Ma Jianjun

Copyright (c) 2021 Liyan Wang et al. This is an open access article distributed under the Creative Commons Attribution License, which permits unrestricted use, distribution, and reproduction in any medium, provided the original work is properly cited.

\begin{abstract}
Modern coastal cities continue to expand to the sea, but the marine silt foundation has high water content and poor bearing capacity. Therefore, it is necessary to find economical and rapid ways to reduce the water content of the silt and improve the bearing capacity of the silt foundation. The steel slag is considered to be incorporated into silt to effectively reduce the moisture content of soil and improve the bearing capacity of the foundation due to its hard texture and strong water absorption capacity. In this paper, the shear strength characteristics of marine silt modified by steel slag were studied using an automatic triaxial instrument, as well as the relationship between steel slag incorporation and modified silt density. Experimental results showed that the incorporation of steel slag can effectively improve the shear strength of the silt. Besides, the influences of water content, steel slag incorporation, and confining pressure on the stress-strain curve characteristics and failure deviatoric stress of modified silt were also analyzed. The addition of steel slag increases the failure deviatoric stress of the silt. However, the increase of water content will weaken the effect of steel slag incorporation. The shear strength index of improved silt with different steel slag incorporation was compared with that of traditional soil, verifying the feasibility of its application in engineering construction.
\end{abstract}

\section{Introduction}

Guan et al. [1] reported that marine silt is a kind of structural soft soil which mainly composed of very fine clay jelly and was accompanied by microorganisms and organics, deposited in still water or slow flowing water environment. Cui [2] has shown that steel slag has the characteristics of hard texture, high compressive strength, strong water resistance, and stable performance after aging. It was also found that steel slag has many internal pores and similar properties to sand soil. Deng et al. [3] used quicklime to treat dredged silt with high moisture content. It was found that the addition of quicklime can effectively reduce the plasticity index of silt, and the more obvious the effect was, the lower the initial moisture content of silt was. Zhang et al. [4] studied the relationship between the moisture content of silt and the incorporation of quicklime. They demonstrated that the relationship between the decreasing ratio of water content of silt and lime mixing ratio is independent of the initial water content of soil. They also found the moisture content of soil decreases linearly with the increase of the lime mixing ratio.

Cai [5] conducted physical and mechanical tests by adding different proportions of lime and fly ash into the silt. It was found that, in the solidification process, adding appropriate amount of fly ash can effectively reduce the moisture content of the silt and improve the unconfined compressive strength of the soil. In addition, with the increase of fly ash incorporation, the stress-strain curve of soil would transit from the softening type to the hardening type. Xie et al. [6] obtained the intensity, maximum dry density, no side-free compressive strength of the cured soil using desulfurization ash, steel slag, and slag to solidify the dredged silt. Through a series of single mixing and shear strength tests of curing materials, Shi et al. [7] concluded that $2 \%$ composite water glass, $3 \%$ raw gypsum, and $0.5 \%$ caustic soda have the best curing effect on dredging silt. Considering comprehensively, the single incorporation of $0.04 \%$ triethanolamine has the highest cost performance. 
Chen et al. [8], through a mechanical study on adding resin to silt, found that the incorporation of superabsorbent resin could effectively delay the reduction of water content of solidified silt soil. The resin in the soil would provide a guarantee for the hydration reaction through the internal water supply, to ensure that the hydration reaction could be carried out to the maximum extent. Chen et al. [9] used incineration bottom ash to solidify dredged silt, analyzing the improvement of silt particle grading and water reduction effect of bottom ash incorporation.

Aiming at saline dredged silt, Peng et al. [10] verified the possibility of applying compound solidified saline dredged silt as a lightweight roadbed filler through curing tests of phosphogypsum and rubber powder. Wang et al. [11] studied the compressive strength characteristics of steel slag-LSBS lightweight sand mixture through unconfined compressive strength tests. They found that the elastic ultimate stress and compressive strength of the mixture had a linear growth trend with the increase of steel slag incorporation. In addition, according to the strength characteristics of the mixture, the optimum mixing ratio and age of steel slag are determined to be $5 \%$ and 28 days, respectively. Li et al. [12] found that the mixed application of steel slag and sand in soft soil foundations could effectively improve the bearing capacity of the foundation and reduce the settlement of the foundation. Sun et al. [13] found that the addition of 10\% 20\% blast furnace slag could improve the expansion characteristics of expansive soil through an experimental study. Wang et al. [14] investigated the influence of steel slag incorporation and curing age on the shear strength characteristics of mixed lightweight clay through a strength test.

Yildirim and Prezzi [15] carried a series of particle size tests, microtests, and geotechnical tests on slag from a steel slag plant in Indiana. They concluded that both fresh steel slag and aged BOF slag had good geotechnical adaptability, which could be used in geotechnical backfill.

The focus of this paper is on the shear strength characteristics of silt improved by steel slag using the static triaxial test. The test scheme was determined, and the density of silt soil under different steel slag incorporation was obtained. The effects of confining pressure, steel slag incorporation and water content on stress-strain characteristics, and failure deviatoric stress of soil mass were analyzed. The shear strength index of the soil with different steel slag incorporation was obtained. Compared with the traditional soil, the shear strength performance of the filler and its applicability in engineering were analyzed.

\section{Test Plan}

The converter aged steel slag produced in the steelmaking process of Zhangjiagang Yonggang Group was used. The grading curve determined by the particle screening test is shown in Figure 1. The silt was taken from the reclamation site of Haibin Avenue in Lianyungang, which is mainly composed of illite and montmorillonite. The silt has the characteristics of high moisture content, poor water permeability, long sedimentation time, and no fluidity. Its relevant physical parameters are shown in Table 1.
The silt used in the test was prepared according to the remolded sample, and the moisture content was controlled to be $50 \%$, and the particle size of the incorporated steel slag was no more than $2 \mathrm{~mm}$. The influence of steel slag incorporation ratio $\alpha_{s}$ on the shear strength of the improved silt was studied, where $\alpha_{s}$ was determined by formula (1). In the preparation process of steel slag silt, it was found that when the steel slag incorporation ratio $\alpha_{s}$ was less than 30 , the sample with high moisture content improved silt in the soft plastic state. Thus, the adsorption force between the sample and the mold was strong, and the demoulding was difficult. When the steel slag incorporation ratio $\alpha_{s}$ was more than $70 \%$, the sample surface was relatively dry due to the moisture being absorbed by the steel slag. The cohesiveness of the sample particles was poor under the condition of dead weight. Thus, it was easy to be disturbed during sampling, which caused some samples to fall off and made it difficult to load samples. Finally, according to the actual situation of the preparation, the steel slag incorporation ratio $\alpha_{s}$ was determined to be $30 \%, 40 \%, 50 \%, 60 \%$, and $70 \%$.

To study the strength characteristics of silt solidified soil with different water content, the triaxial sample preparation was carried out on the silt with higher water content. It was found that the sample formed well when the steel slag incorporation ratio $\alpha_{s}$ was between $70 \%$ and $110 \%$. For unifying compared, it was determined that the silt had water content of $70 \%$ and $90 \%$ and the corresponding steel slag incorporation ratio $\alpha_{s}$ was $70 \%, 90 \%$, and $110 \%$, respectively. The triaxial test scheme of improving marine silt with steel slag is shown in Table 2, and specific test conditions are shown in Table 3. For the convenience of recording, the marine silt improved with steel slag is recorded as MS-CSS (marine slime mixed with coarse steel slag). The shear strength characteristics of three groups of silt under different moisture content, steel slag incorporation, and confining pressure were measured in the test totally. Among the silt soil with the moisture content $\omega$ of $50 \%$, the steel slag mixing ratio $\alpha_{s}$ was controlled to be $30 \%$, $40 \%, 50 \%, 60 \%$, and $70 \%$, respectively. In the silt soil with water content $\omega$ of $70 \%$ and $90 \%$, the steel slag incorporation ratio was the same, which were $70 \%, 90 \%$, and $110 \%$. There were 11 groups of working conditions. The samples in each group of working conditions should be tested under the confining pressure of $100 \mathrm{kPa}, 200 \mathrm{kPa}$, and $300 \mathrm{kPa}$, respectively, and three groups of parallel tests under the same confining pressure. A total of 99 samples were measured.

Due to the large internal pores of steel slag, its incorporation into silt soil will improve the water permeability of the soil, so the triaxial consolidation and drainage test was considered. The stress-strain relationship of soil under different steel slag incorporation was measured, and the deviatoric stress of shear failure was obtained. The stress Mohr circle was drawn, and the relationship between the shear strength characteristics of the filler and the steel slag incorporation was obtained:

$$
\alpha_{s}=\frac{m_{\mathrm{ss}}}{m_{\mathrm{ms}}}
$$

where $m_{\mathrm{ss}}$ is the quality of steel slag and $m_{\mathrm{ms}}$ is the quality of marine silt. 


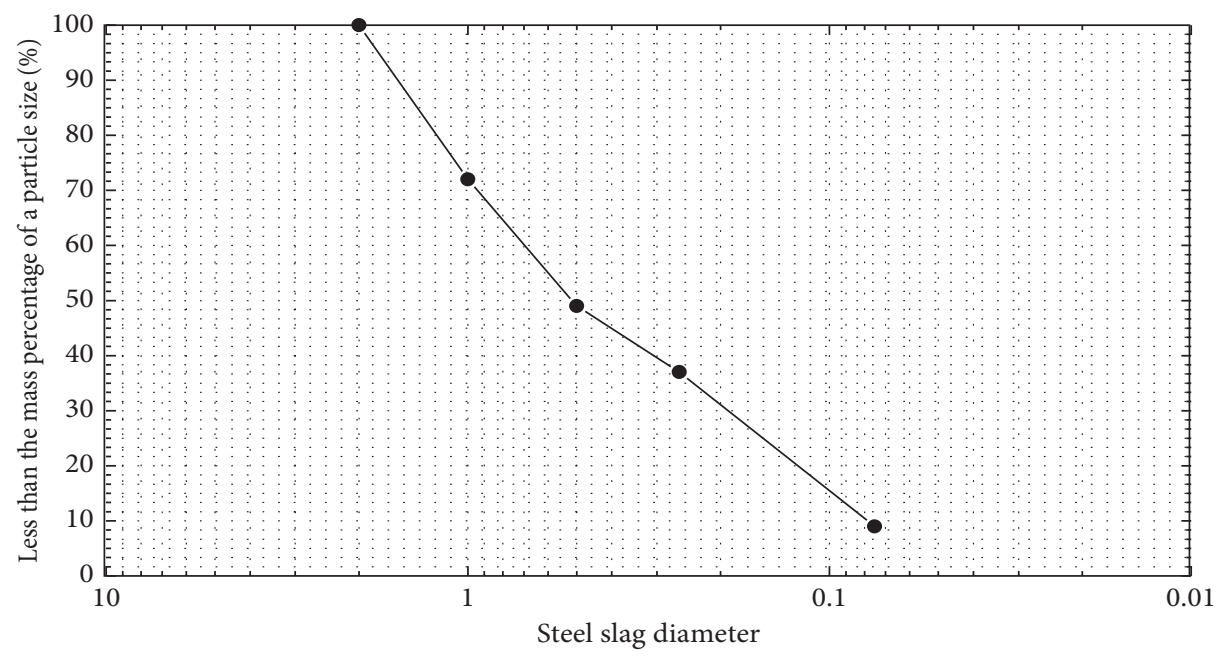

Figure 1: Curve of steel slag grading.

TABle 1: Physical properties of the test soil.

\begin{tabular}{|c|c|c|c|c|c|c|}
\hline $\begin{array}{l}\text { Moisture content } \omega \\
(\%)\end{array}$ & $\begin{array}{c}\text { Void ratio } \\
e\end{array}$ & $\begin{array}{l}\text { Specific gravity of particles } \\
G_{S}\end{array}$ & $\begin{array}{l}\text { Density } \rho \\
\left(\mathrm{g} / \mathrm{cm}^{3}\right)\end{array}$ & $\begin{array}{l}\text { Liquid limit } \omega_{L} \\
\text { (\%) }\end{array}$ & $\begin{array}{c}\text { Plastic limit } \omega_{p} \\
(\%)\end{array}$ & Organic content (\%) \\
\hline 50 & 1.51 & 2.74 & 1.62 & 42.8 & 31.7 & 3.4 \\
\hline 70 & - & - & 1.46 & - & - & - \\
\hline 90 & - & - & 1.31 & - & - & - \\
\hline
\end{tabular}

TABLe 2: Static triaxial test conditions of the sample.

\begin{tabular}{lc}
\hline & Triaxial test type: CD \\
Parameters & Numerical value \\
\hline Confining pressure $(\mathrm{kPa})$ & 100,200 , and 300 \\
Particle size of the steel slag $d_{r}(\mathrm{~mm})$ & $\leq 2 \mathrm{~mm}$ \\
Steel slag incorporation ratio $\alpha_{s}(\%)($ silt water content $50 \%)$ & $30 \%, 40 \%, 50 \%, 60 \%$, and $70 \%$ \\
Particle size of the steel slag $\alpha_{r}(\%)($ silt water content $70 \%$ and $90 \%)$ & $70 \%, 90 \%$, and $110 \%$ \\
\hline
\end{tabular}

Field photos of steel slag and silt mixing soil samples and triaxial samples prepared under specific working conditions are shown in Figures 2-4, respectively.

As can be seen from Figure 2, in the silt with 50\% moisture content, when the steel slag incorporation was less, such as $\alpha_{s}=30 \%$, the clay soil characteristics of the filler were more obvious, and the cohesion between particles was higher after mixing. With the increase of steel slag incorporation, the properties of sand on the surface of fillers become more and more obvious, and the grain sense is gradually enhanced. Figures 3 and 4 show that the transition characteristics of the silt samples with $70 \%$ and $90 \%$ moisture content changing from clay characteristics to sand characteristics with the increase of steel slag incorporation were basically the same as characteristics of the silt with $50 \%$ moisture content.

\section{Analysis of Experimental Results}

3.1. The Sample Density. After the completion of the production of triaxial samples, the mass of the three groups of parallel test samples under each group of working conditions was weighed to calculate the corresponding average density, as shown in Table 4 . Based on the data in the table, the relationship curve of sample density with steel slag incorporation change under different water content conditions is plotted in Figure 5.

Figure 5 shows that, with $50 \%$ moisture content, the density of the sample kept increasing, but the growth rate kept decreasing with the increase of steel slag incorporation. The improved silt density was $1.79 \mathrm{~g} / \mathrm{cm}^{3}$ when the steel slag incorporation was $30 \%$. Compared with $1.62 \mathrm{~g} / \mathrm{cm}^{3}$ of pure silt, the improved silt increased $0.17 \mathrm{~g} / \mathrm{cm}^{3}$, a $10.5 \%$ increase in density. The improved silt density was $1.92 \mathrm{~g} / \mathrm{cm}^{3}$ when the steel slag incorporation was $40 \%$, and compared with $30 \%$ steel slag incorporation, a $7.3 \%$ increase in density. The improved silt with $50 \%$ steel slag incorporation had a $3.6 \%$ increase in density compared with the silt with $40 \%$ steel slag. The improved silt with $60 \%$ steel slag incorporation had a $2.5 \%$ increase in density compared with the silt with $50 \%$ steel slag. However, the improved silt density with $70 \%$ steel slag incorporation was the same as that with $60 \%$ steel slag incorporation, which was $2.07 \mathrm{~g} / \mathrm{cm}^{3}$. It can be concluded that the density of the sample increases with the increase of the steel slag incorporation considering the experimental error components in density measurement. However, the 
TABle 3: Triaxial test specific working conditions' table.

\begin{tabular}{|c|c|c|c|c|}
\hline Condition number & Moisture content $\omega(\%)$ & Steel slag incorporation $\alpha_{s}(\%)$ & Sample density $\rho\left(\mathrm{g} / \mathrm{cm}^{3}\right)$ & Confining pressure $(\mathrm{kPa})$ \\
\hline MS-CSS11-1 & & & 1.52 & 100 \\
\hline MS-CSS11-2 & & 30 & 1.49 & 200 \\
\hline MS-CSS11-3 & & & 1.55 & 300 \\
\hline MS-CSS12-1 & & & 1.50 & 100 \\
\hline MS-CSS12-2 & & 40 & 1.51 & 200 \\
\hline MS-CSS12-3 & & & 1.49 & 300 \\
\hline MS-CSS13-1 & & & 1.47 & 100 \\
\hline MS-CSS13-2 & 50 & 50 & 1.45 & 200 \\
\hline MS-CSS13-3 & & & 1.49 & 300 \\
\hline MS-CSS14-1 & & & 1.39 & 100 \\
\hline MS-CSS14-2 & & 60 & 1.43 & 200 \\
\hline MS-CSS14-3 & & & 1.47 & 300 \\
\hline MS-CSS15-1 & & & 1.48 & 100 \\
\hline MS-CSS15-2 & & 70 & 1.42 & 200 \\
\hline MS-CSS15-3 & & & 1.45 & 300 \\
\hline MS-CSS21-1 & & & 1.57 & 100 \\
\hline MS-CSS21-2 & & 70 & 1.53 & 200 \\
\hline MS-CSS21-3 & & & 1.61 & 300 \\
\hline MS-CSS22-1 & & & 1.50 & 100 \\
\hline MS-CSS22-2 & 70 & 90 & 1.51 & 200 \\
\hline MS-CSS22-3 & & & 1.52 & 300 \\
\hline MS-CSS23-1 & & & 1.44 & 100 \\
\hline MS-CSS23-2 & & 110 & 1.48 & 200 \\
\hline MS-CSS23-3 & & & 1.46 & 300 \\
\hline MS-CSS31-1 & & & 1.69 & 100 \\
\hline MS-CSS31-2 & & 70 & 1.73 & 200 \\
\hline MS-CSS31-3 & & & 1.77 & 300 \\
\hline MS-CSS32-1 & & & 1.53 & 100 \\
\hline MS-CSS32-2 & 90 & 90 & 1.57 & 200 \\
\hline MS-CSS32-3 & & & 1.61 & 300 \\
\hline MS-CSS33-1 & & & 1.53 & 100 \\
\hline MS-CSS33-2 & & 110 & 1.52 & 200 \\
\hline MS-CSS33-3 & & & 1.54 & 300 \\
\hline
\end{tabular}

Note. Numbering notes. Silt moisture content was divided into three levels $50 \%, 70 \%$, and $90 \%$, corresponding to numbers 1 , 2, and 3 . The steel slag incorporation in silt soil with $50 \%$ moisture content is divided into five grades: $30 \%, 40 \%, 50 \%, 60 \%$, and $70 \%$, corresponding to numbers $1,2,3,4$, and 5 . The steel slag incorporation ratio in silt soil with $70 \%$ and $90 \%$ moisture content are divided into five grades: $30 \%, 40 \%, 50 \%, 60 \%$, and $70 \%$, corresponding to numbers $1,2,3,4$, and 5 . The first number represents the silt moisture content, the second number represents the steel slag incorporation ratio, and the third number represents the parallel test number.

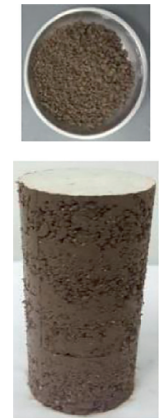

(a)

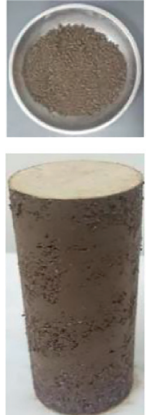

(b)

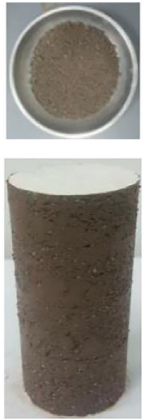

(c)

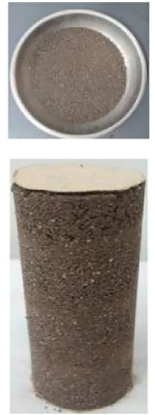

(d)

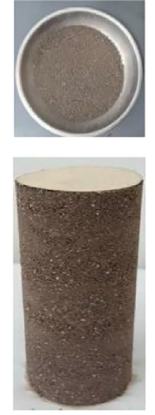

(e)

Figure 2: The triaxial mixture sample of different steel slag.

(a) $\alpha_{s}=30 \%$. (b)

(b) $\alpha_{s}=40 \%$

(c) $\alpha_{s}=50 \%$.

(d) $\alpha_{s}=60 \%$. (e) $\alpha_{s}=70 \%$.

increasing amplitude decreases, and the density of the sample tends to be stable at last.

In the silt with $70 \%$ and $90 \%$ moisture content, with the addition of steel slag, the sample density increased rapidly at the beginning, and the growth rate decreased at the later stage. In the silt with a moisture content of $70 \%$, the density of $70 \%$ steel slag incorporation was $1.91 \mathrm{~g} / \mathrm{cm}^{3}$, which was $0.45 \mathrm{~g} / \mathrm{cm}^{3}$ higher than that of pure silt with a density of $1.46 \mathrm{~g} / \mathrm{cm}^{3}$, an increase of $31 \%$. Compared with the silt with the $70 \%$ steel slag incorporation, the soil density with $90 \%$ increased $4.2 \%$, and the density of $110 \%$ steel slag incorporation had a $4 \%$ increase compared with $90 \%$. In the silt 

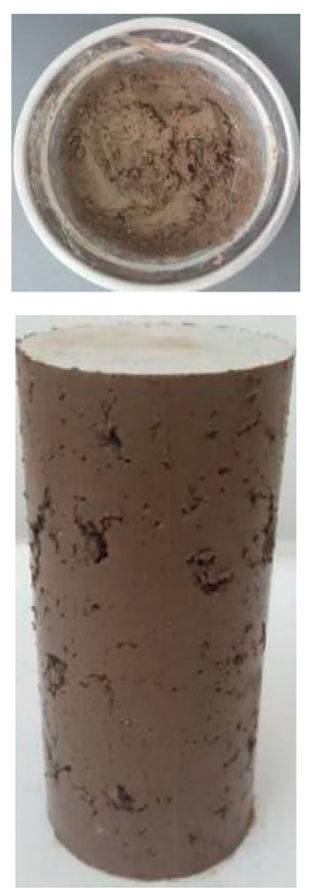

(a)
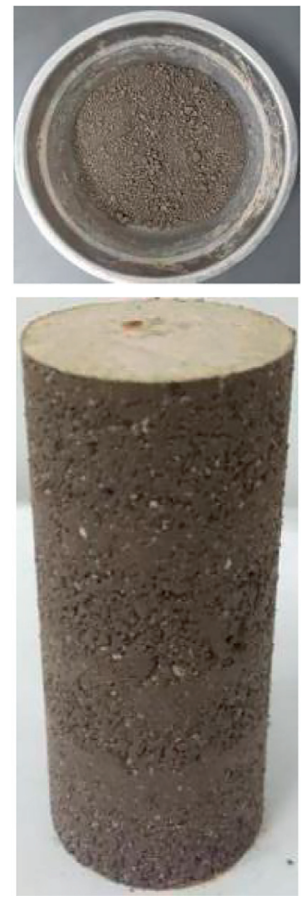

(b)
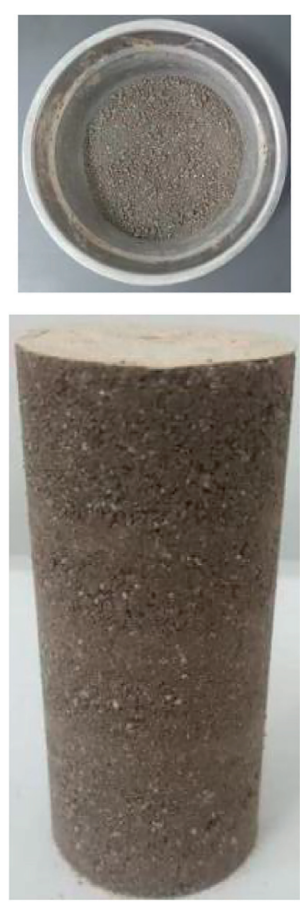

(c)

FiguRE 3: The triaxial mixture sample of different steel slag incorporation $\left(\omega=70 \%\right.$ ). (a) $\alpha_{s}=70 \%$. (b) $\alpha_{s}=90 \%$. (c) $\alpha_{s}=110 \%$.
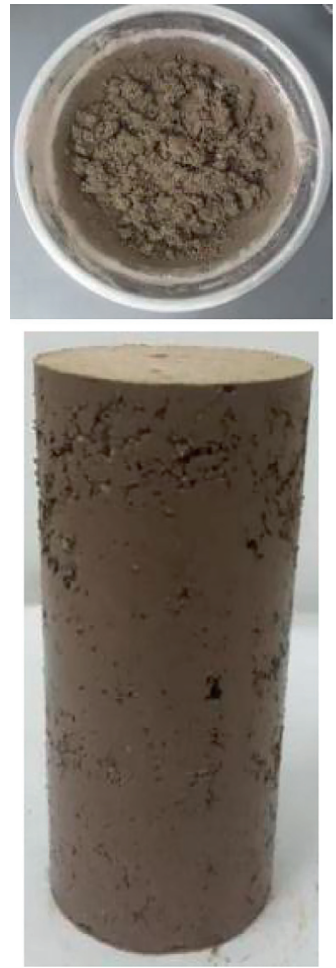

(a)
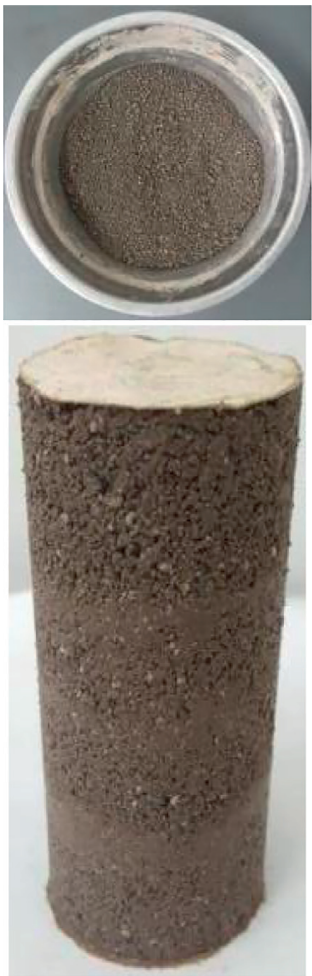

(b)
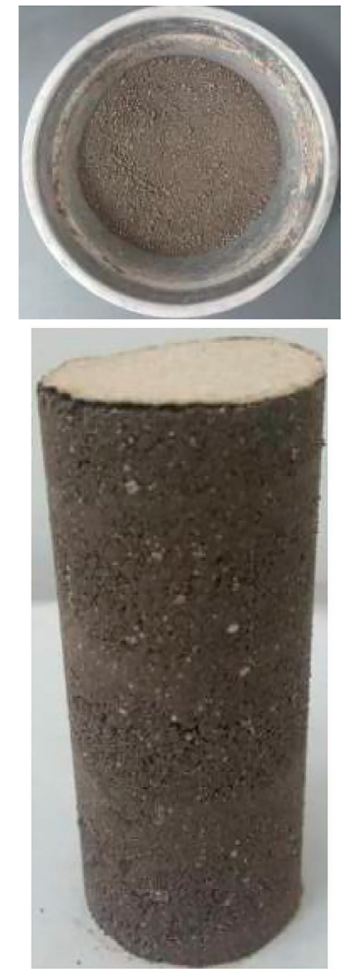

(c)

Figure 4: The triaxial mixture sample of different steel slag incorporation ( $\omega=90 \%$ ). (a) $\alpha_{s}=70 \%$. (b) $\alpha_{s}=90 \%$. (c) $\alpha_{s}=110 \%$. 
TABle 4: Density of samples.

\begin{tabular}{|c|c|c|c|c|c|c|}
\hline \multicolumn{7}{|c|}{ Moisture Content: $50 \%$} \\
\hline Steel slag incorporation ratio $\alpha_{s}(\%)$ & 0 & 30 & 40 & 50 & 60 & 70 \\
\hline Density $\rho\left(\mathrm{g} / \mathrm{cm}^{3}\right)$ & 1.62 & 1.79 & 1.92 & 1.99 & 2.04 & 2.04 \\
\hline \multicolumn{7}{|c|}{ Moisture Content: $70 \%$} \\
\hline Steel slag incorporation ratio $\alpha_{s}(\%)$ & 0 & & & & & 110 \\
\hline Density $\rho\left(\mathrm{g} / \mathrm{cm}^{3}\right)$ & 1.46 & & & & & 2.07 \\
\hline \multicolumn{7}{|c|}{ Moisture Content: $90 \%$} \\
\hline Steel slag incorporation ratio $\alpha_{s}(\%)$ & 0 & & & & & 110 \\
\hline Density $\rho\left(\mathrm{g} / \mathrm{cm}^{3}\right)$ & 1.31 & & & & & 2.07 \\
\hline
\end{tabular}

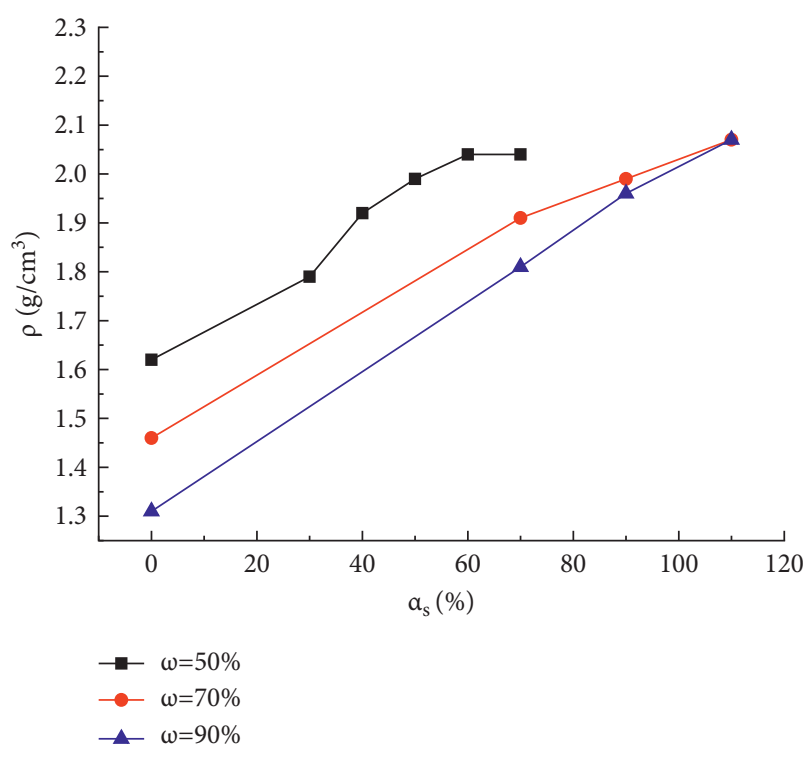

Figure 5: Density of the sample.

with $90 \%$ moisture content, the density changes were $38 \%$, $8.3 \%$, and $5.6 \%$, respectively. The density data change shows that the density of the sample kept increasing, but the growth amplitude kept decreasing as the steel slag incorporation increased where all other parameters were the same.

Taken together, the steel slag modified silt soil density increased with the increase of steel slag incorporation under the same compaction condition, but the increase gradually reduced to a flat level. This is because of the high compressive strength of the steel slag itself. With the continuous addition of steel slag, the particle properties of the sample become more and more obvious, and it is not easy to be compacted. Thus, the density of the sample tends to be stable with the influence of the steel slag compactness.

\subsection{The Stress-Strain Curve of the Sample}

3.2.1. Characteristic Description of Stress-Strain Curve. Figure 6 shows the relationship between the principal stress difference $\left(\sigma_{1}-\sigma_{3}\right)$ and axial strain $\left(\varepsilon_{1}\right)$ of the silt with $50 \%$ moisture content at $100 \mathrm{kPa}, 200 \mathrm{kPa}$, and $300 \mathrm{kPa}$ confining pressure under the conditions that the steel slag mixing ratio $\alpha_{s}$ was $30 \%, 40 \%, 50 \%, 60 \%$, and $70 \%$, namely, the stressstrain curve.

Figures 7 and 8 show the stress-strain curves of the silt with water content of $70 \%$ and $90 \%$, respectively, under the condition that the steel slag incorporation ratio $\alpha_{s}$ was $70 \%$, $90 \%$, and $110 \%$.

Figures 7 and 8 also show that the stress-strain curves of steel slag-solidified silt samples with different water content were up convex type. The stress of the samples increased with the increase of axial strain during the shear process, but the increasing amplitude decreased continuously, with no obvious peak value in the curve within the strain range of $15 \%$. According to the above curve characteristics, the stress-strain curve of the sample is the strain hardening type. The failure mode of the samples is similar to that of conventional sand and normally consolidated clay, which is an ideal elastoplastic failure mode.

Figure 9 shows the shape of the modified sample after shear failure, which was large in the middle and small on both sides, namely, a typical drum failure. The reason is that the sample was mainly based on silty soft soil, so the friction constraint on the upper and lower surfaces was larger than that on the middle of the sample during the loading process. Therefore, in the process of compression, the failure form was large in the middle and small at both ends, which is also the common failure mode of soft clay in the triaxial test.

\subsubsection{Influence of Confining Pressure on Stress-Strain Curve} Characteristics. In order to facilitate comparison, the stressstrain curves of the samples with all other same parameters were selected to compare the influence of confining pressure on the stress-strain curve characteristics of the samples. Take the sample with 50\% moisture content and 30\% steel slag incorporation as an example, as shown in Figure 5. It can be seen that the stress-strain curves of the samples under different confining pressures are basically the same, which are the strain hardening type. The stress amplitude of the curve increases under the same strain condition with the increase of confining pressure. In addition, the curve stress-strain characteristics of other samples are basically the same, which shows that the increase of confining pressure can increase the stress amplitude of the curve but has little effect on the line type of stress-strain curves. The reason is that the external force acting on the sample surface increased with the increase of confining pressure, which led to the volume of the sample compressed and the spacing between particles decreased, and the connection became closer. Therefore, the antideformation ability of soil was improved.

3.2.3. Influence of Steel Slag Incorporation on Stress-Strain Curve Characteristics. In order to compare the influence of steel slag incorporation on the stress-strain profile of the 


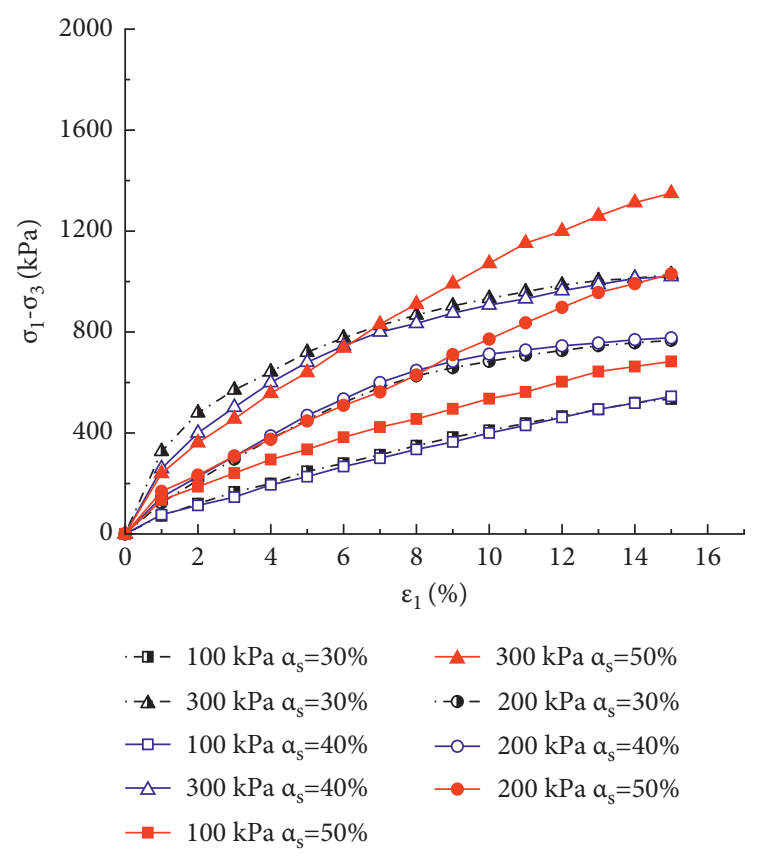

(a)

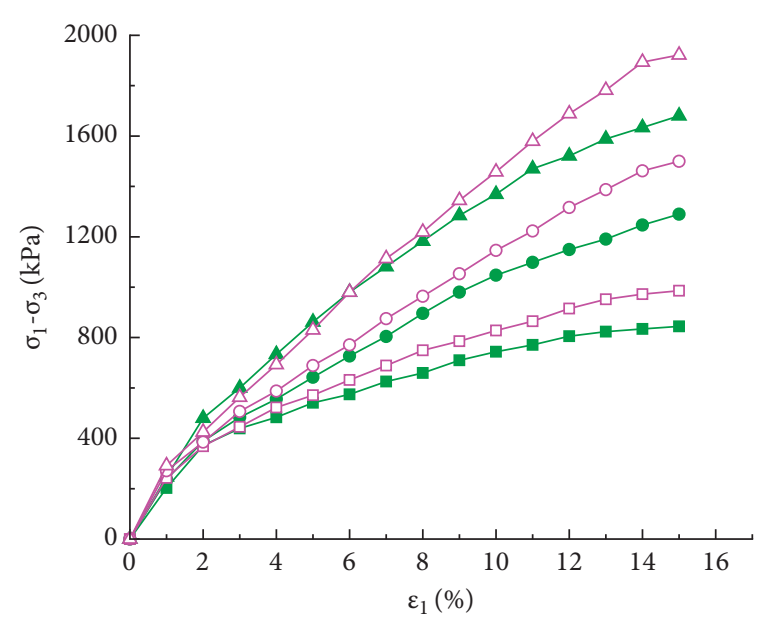

$\begin{array}{ll}\rightarrow-100 \mathrm{kPa} \alpha_{\mathrm{s}}=60 \% & -\square 100 \mathrm{kPa} \alpha_{\mathrm{s}}=70 \% \\ -200 \mathrm{kPa} \alpha_{\mathrm{s}}=60 \% & -0200 \mathrm{kPa} \alpha_{\mathrm{s}}=70 \% \\ -300 \mathrm{kPa} \alpha_{\mathrm{s}}=60 \% & -\triangle 300 \mathrm{kPa} \alpha_{\mathrm{s}}=70 \%\end{array}$

(b)

FIGURE 6: Relationship between principal stress difference and axial strain $(\omega=50 \%)$.

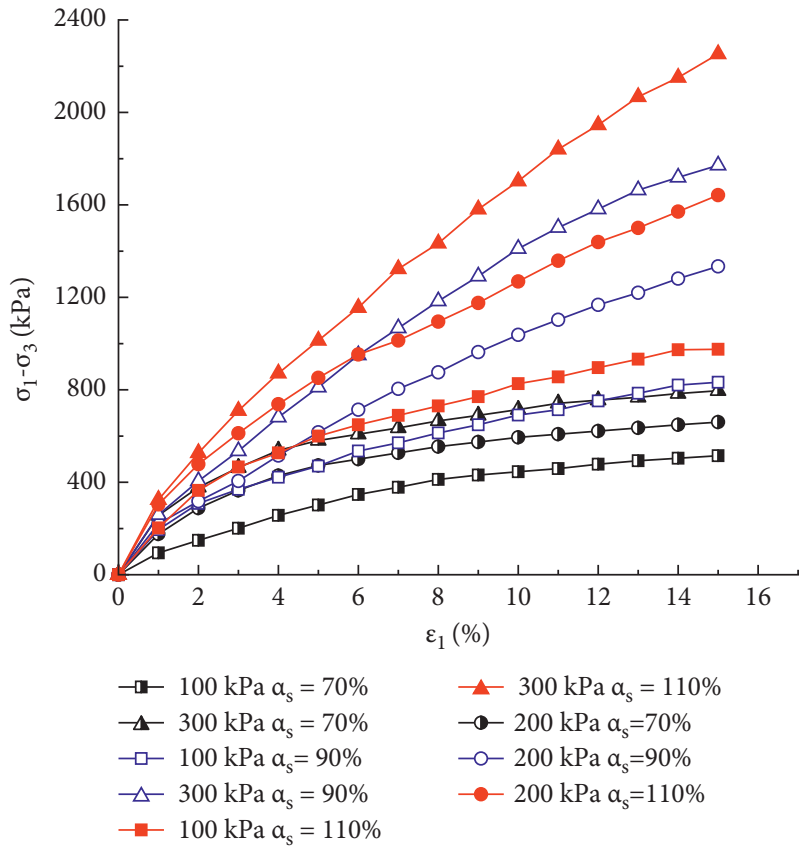

FIGURE 7: Relationship between principal stress difference and axial strain $(\omega=70 \%)$.

samples, the stress-strain curves of the samples with different steel slag incorporation, where the water content was the same under the confining pressure of $200 \mathrm{kPa}$, were plotted in Figure 10 for comparison.

Figure 10(a) shows that the stress-strain of the sample begins to show a linear relationship with the increasing incorporation of steel slag when silt has a moisture content of $50 \%$. Especially, for the steel slag incorporation $\alpha_{s} \geq 50 \%$,

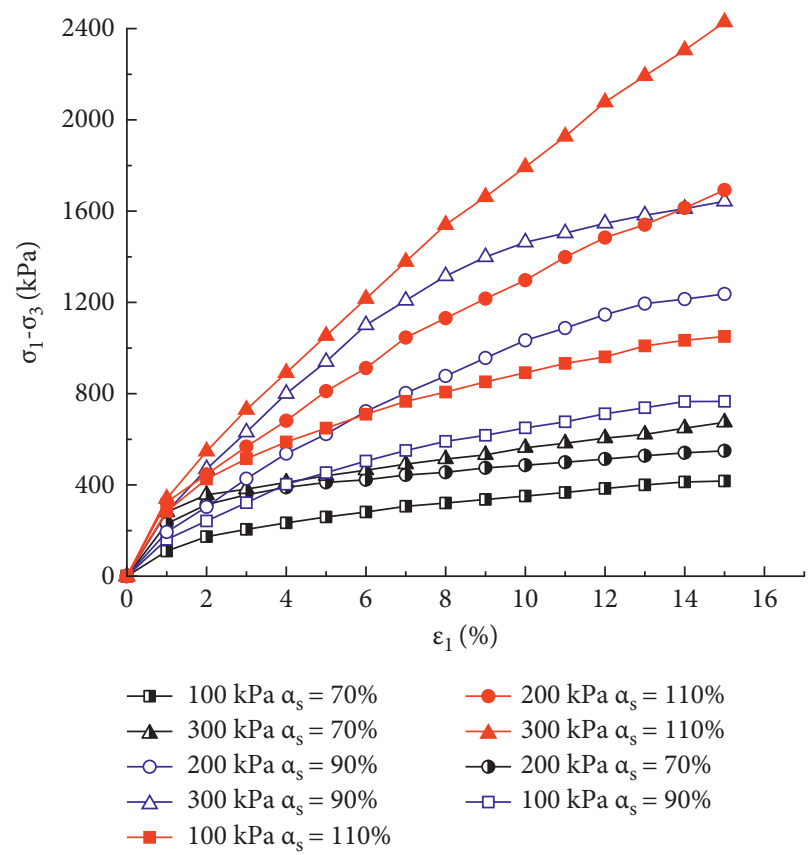

FIGURE 8: Relationship between principal stress difference and axial strain $(\omega=90 \%)$

the linear characteristics of the curve are obvious. Figures 10(b) and 10(c) show that the curves of silt with different water content are also gradually transiting to linearity with the increase of steel slag incorporation among silts with water content of $70 \%$ and $90 \%$. In particular, for the steel slag incorporation $\alpha_{s} \geq 90 \%$, the linear characteristics of the stress-strain curve of the sample are obvious. These results show that the structure of the soil can be 


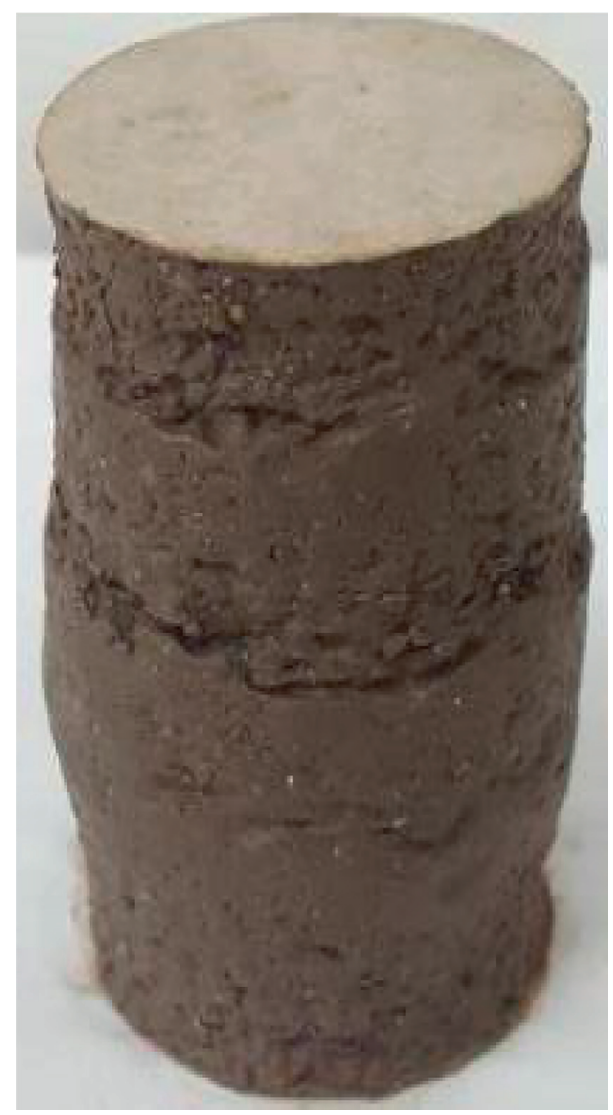

FIGURE 9: Failure form of the modified sample.

obviously strengthened by adding more than $90 \%$ steel slag into the silt when the water content of the silt was high.

Taken together, the stress-strain curves of silt with different water content will gradually transmit to linearity with the increase of steel slag incorporation. The reason is that the steel slag has a hard texture and a large compressive strength, and the skeleton effect became more and more obvious after the steel slag was combined with silt with the increase of steel slag incorporation. Hence, the structure of the sample was enhanced and the elastic deformation capacity of the soil was enhanced. Figure 10 also shows that the amplitude of the stress-strain curves of the sample increases with the increase of steel slag incorporation, meaning that the antideformation ability of the packing was enhanced.

\subsubsection{Influence of Water Content on Stress-Strain Curve} Characteristics. In order to compare the influence of water content on the stress-strain characteristics of the curve, the stress-strain curves of samples with $70 \%$ steel slag incorporation (i.e., $\alpha_{s}=70 \%$ ) under $50 \%, 70 \%$, and $90 \%$ water content were compared under $200 \mathrm{kPa}$ confining pressure. Figure 11 shows the stress-strain curves of samples with different water content under the condition of $70 \%$ steel slag incorporation.

It can be seen from the figure that the linear characteristic of the silt curve with 50\% moisture content is obviously better than that of the silt with $70 \%$ and $90 \%$ moisture content after mixed with the same steel slag proportion. In addition, the stress amplitude of the silt with
$50 \%$ moisture content is obviously higher than that of the silt with $70 \%$ and $90 \%$ moisture content. It shows that the silt with low moisture content has higher antideformation ability and structure under the same steel slag incorporation. The reason is that the relative slippage between the samples under pressure was easy to occur because of the presence of water when the water content of the silt was high, which was not conducive to the formation of a good structure. As a result, the linear characteristics of the stress-strain curve of soil are not obvious, and the compressive capacity is relatively low.

Taken together, the characteristics of the stress-strain curve of silt improved by steel slag are the strain hardening type, and the confining pressure has little effect on the characteristics of the stress-strain curve of the filler. Increasing the steel slag incorporation in the silt can enhance the structure of the soil under the same water content. The stronger the structure of silt, the lower the water content of silt under the same steel slag incorporation. In addition, the increase of confining pressure and steel slag incorporation and the decrease of water content of silt are all beneficial to the exertion of elastic deformation capacity of soil as well as the improvement of antideformation capacity of soil.

\subsection{Influence of Steel Slag Incorporation, Confining Pressure, and Water Content on the Deviant Stress of Failure}

3.3.1. Influence of Steel Slag Incorporation on Failure Deviatoric Stress. In the process of shear failure, if the stressstrain curve has a peak value, the peak stress should be taken as the failure deviatoric stress. While, the stress corresponding to $15 \%$ of the strain would be taken as the failure deviatoric stress $\left(\sigma_{1}-\sigma_{3}\right)_{f}$ when there is no peak value. The stress of samples under different working conditions increased with the increase of strain during the shear process. Therefore, the stress corresponding to $15 \%$ strain was taken as the failure deviatoric stress. The failure deviatoric stresses of the samples with different steel slag incorporation under different confining pressures are shown in Table 5. The relationship curve between failure deviatoric stress and steel slag incorporation is shown in Figure 12.

Figure 12 shows that the relationship curves between failure deviatoric stress and steel slag incorporation of samples under different confining pressures with the same water content are the same. The failure deviatoric stress of the sample did not increase significantly when the steel slag incorporation increased from $30 \%$ to $40 \%$ in the silt with $50 \%$ moisture content. However, the deviatoric stress increased almost linearly with the steel slag incorporation, and the growth rate was high when the steel slag incorporation $\alpha_{s} \geq 40 \%$. In the silt with water content of $70 \%$ and $90 \%$, the failure deviatoric stress of the sample increased continuously with the addition of steel slag when the steel slag incorporation increased from $70 \%$ to $90 \%$. When the steel slag increases from $70 \%$ to $90 \%$, the increase of failure deviatoric stress was the largest, and the increase decreased from $90 \%$ to $110 \%$. 


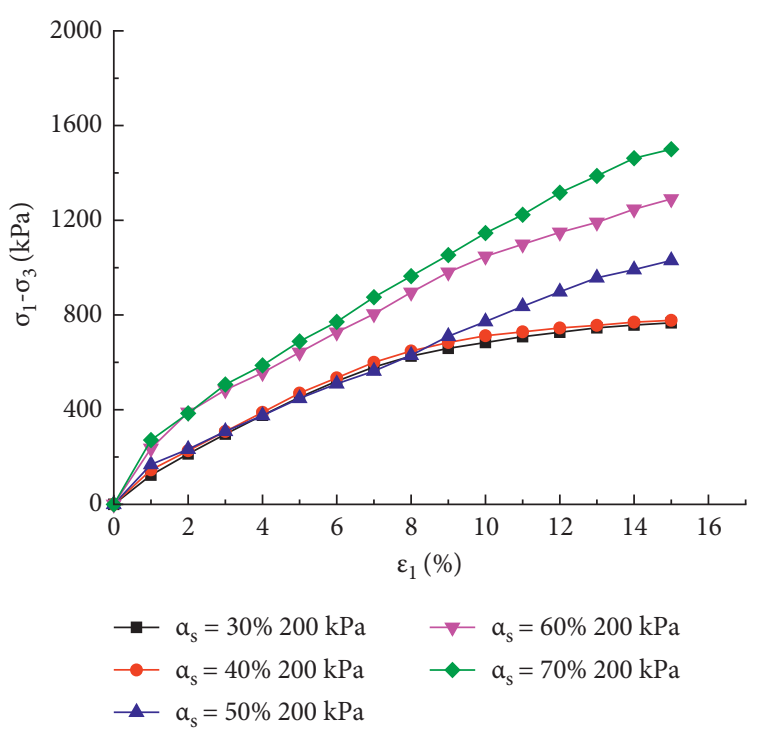

(a)

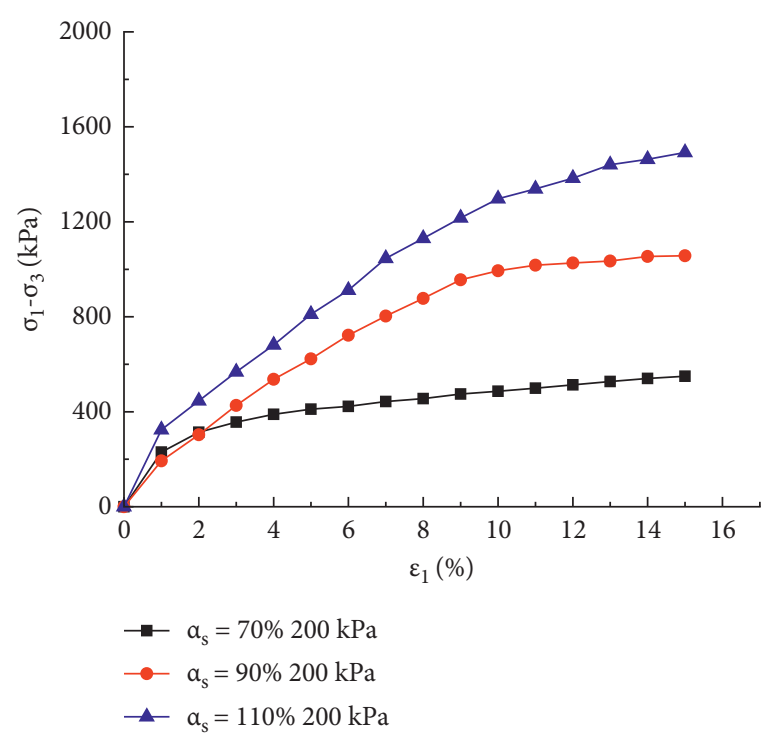

(b)

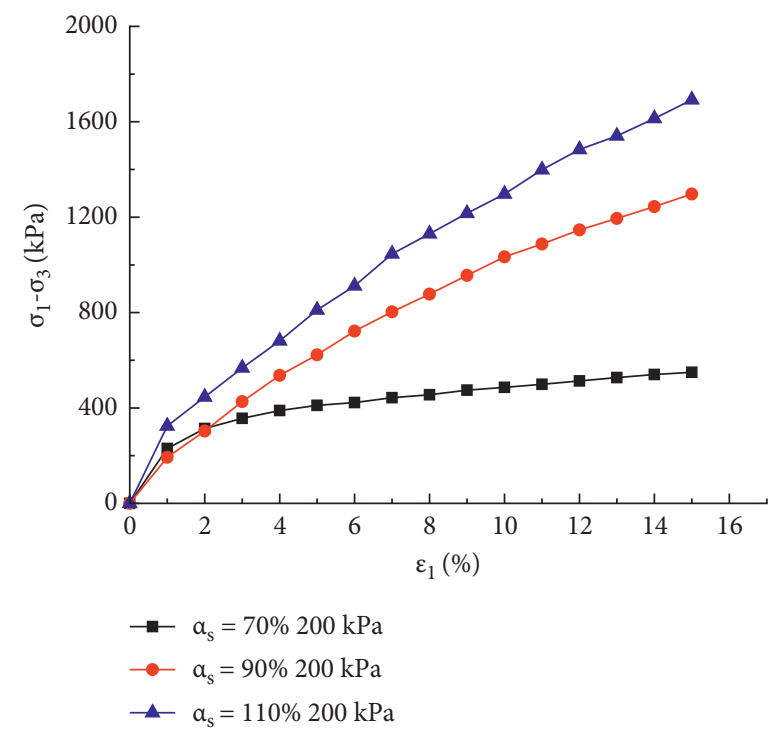

(c)

FiguRE 10: Stress and strain curve of the sample under different water content. (a) $\omega=50 \%$. (b) $\omega=70 \%$. (c) $\omega=90 \%$.

The failure deviatoric stress of the samples increased with the increase of steel slag incorporation showing that the antideformation and failure ability of silt with different water content will be improved with the addition of steel slag incorporation. The failure deviatoric stress values of silt with $70 \%$ and $90 \%$ water content with different steel slag incorporation conditions were similar under the same confining pressure. The results show that the silt with $70 \%$ and $90 \%$ moisture content has similar antideformation and failure ability under the same steel slag incorporation. Under the confining pressure of $100 \mathrm{kPa}$, the failure deviatoric stress of the samples with steel slag incorporation of $30 \%$ and $40 \%$ in the silt with $50 \%$ moisture content was close to that of the samples with steel slag incorporation of $70 \%$ in the silt with $70 \%$ moisture content. In addition, the failure deviatoric stress of the samples with
$60 \%$ and $70 \%$ steel slag incorporation in the silt with $50 \%$ moisture content was close to that of the samples with $70 \%$ and $110 \%$ steel slag incorporation in the silt with $70 \%$ moisture content. Under the confining pressure of $200 \mathrm{kPa}$, the failure deviatoric stress of the samples with $60 \%$ steel slag incorporation in the silt with $50 \%$ moisture content was close to that of the samples with $90 \%$ steel slag incorporation in the silt with $70 \%$ moisture content. Under the confining pressure of $300 \mathrm{kPa}$, the failure deviatoric stress of the samples with $60 \%$ steel slag incorporation in the silt with 50\% moisture content was similar to that of the samples with $90 \%$ steel slag incorporation in the silt with $90 \%$ moisture content. In the steel slag-silt mixture with lower moisture content (i.e., $\omega=50 \%$ ) and less steel slag incorporation, the values of failure deviatoric stress under different confining pressures were close to those of the 


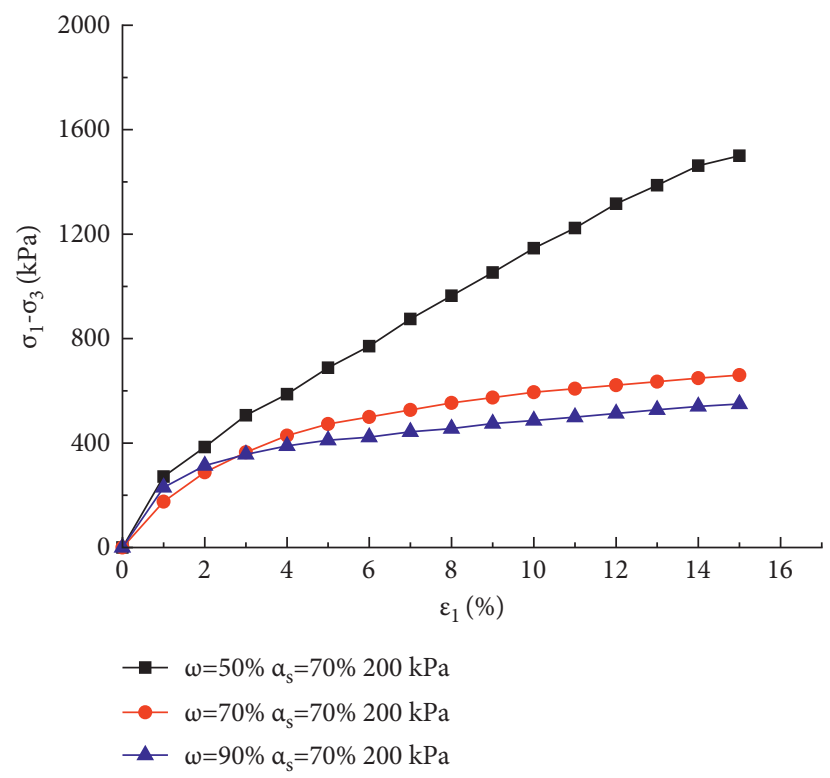

Figure 11: Stress and strain curve of the sample under 70\% steel slag incorporation.

TABLE 5: Failure deviatoric stress of steel slag and silt mixture.

\begin{tabular}{|c|c|c|c|c|}
\hline \multirow{2}{*}{ Silt moisture content $\omega(\%)$} & \multirow{2}{*}{ Steel slag incorporation ratio $\alpha_{s}(\%)$} & \multicolumn{3}{|c|}{ Partial destruction stress $\left(\sigma_{1}-\sigma_{3}\right)_{f}(\mathrm{kPa})$} \\
\hline & & $100 \mathrm{kPa}$ & $200 \mathrm{kPa}$ & $300 \mathrm{kPa}$ \\
\hline \multirow{5}{*}{50} & 30 & 535.2 & 767.6 & 1028.6 \\
\hline & 40 & 545.4 & 777.4 & 1020.2 \\
\hline & 50 & 683.6 & 1030.2 & 1350.3 \\
\hline & 60 & 844.3 & 1290.1 & 1680.4 \\
\hline & 70 & 985.9 & 1500 & 1922.2 \\
\hline \multirow{3}{*}{70} & 70 & 515.1 & 660.4 & 796.1 \\
\hline & 90 & 832.4 & 1334.3 & 1771.4 \\
\hline & 110 & 975.4 & 1642.2 & 2252.4 \\
\hline \multirow{3}{*}{90} & 70 & 416.7 & 549.7 & 674.7 \\
\hline & 90 & 766.2 & 1236.9 & 1642.9 \\
\hline & 110 & 1050.3 & 1692.2 & 2428.3 \\
\hline
\end{tabular}

mixture with more steel slag incorporation in the silt with high moisture content. It shows that adding a small amount of steel slag to the silt with low moisture content can obtain the similar antideformation and failure ability as that of the mixture with high moisture content silt and more steel slag. The incorporation of steel slag will enhance the deformation resistance of the silt as well as the antideformation and failure ability of low water content silt increased rapidly with the incorporation of steel slag.

\subsubsection{Influence of Confining Pressure on Failure Deviatoric} Stress. Figure 12 shows that the relationship curve line type between failure deviatoric stress of the improved silt and steel slag incorporation under confining pressure at all levels is the same. Under the condition of each level of steel slag incorporation, the failure deviatoric stress increased proportionally with the confining pressure increasing. It shows that the improved silt has the compaction-hardening characteristics common to general fillers and the increase of the resistance to deformation and failure of the improved silt is almost proportional to the increase of the confining pressure.

3.3.3. Influence of Moisture Content on Failure Deviatoric Stress. For the convenience of comparison, silts with steel slag incorporation of $70 \%$ in three kinds of water content are selected from Table 5 for comparison, and the relationship curve between failure deviatoric stress and water content is plotted in Figure 13.

As can be seen from the figure, under the same steel slag incorporation condition, the failure deviatoric stress of the improved silt tends to decrease continuously with the increasing water content of the silt, but the decreasing extent becomes smaller and smaller. When the water content of the improved silt increases from $50 \%$ to $70 \%$, the failure deviatoric stress decreased most obviously. The decreasing amplitude, respectively, are 50\%, 53.3\% and 55.2\% under $100-300 \mathrm{kPa}$ confining pressure. When water content increased from $70 \%$ to $90 \%$, the failure deviatoric stress decreasing amplitude, respectively, are 19\%, 16.7\%, and $15.2 \%$. 


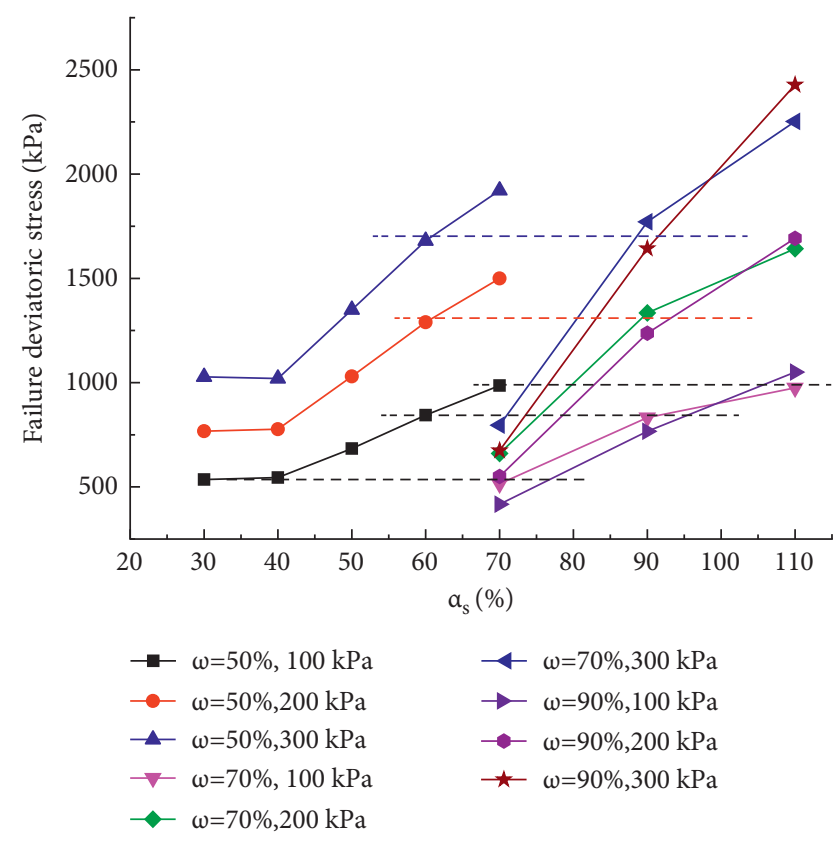

FIGURE 12: Relationship between failure deviatoric stress and steel slag incorporation.

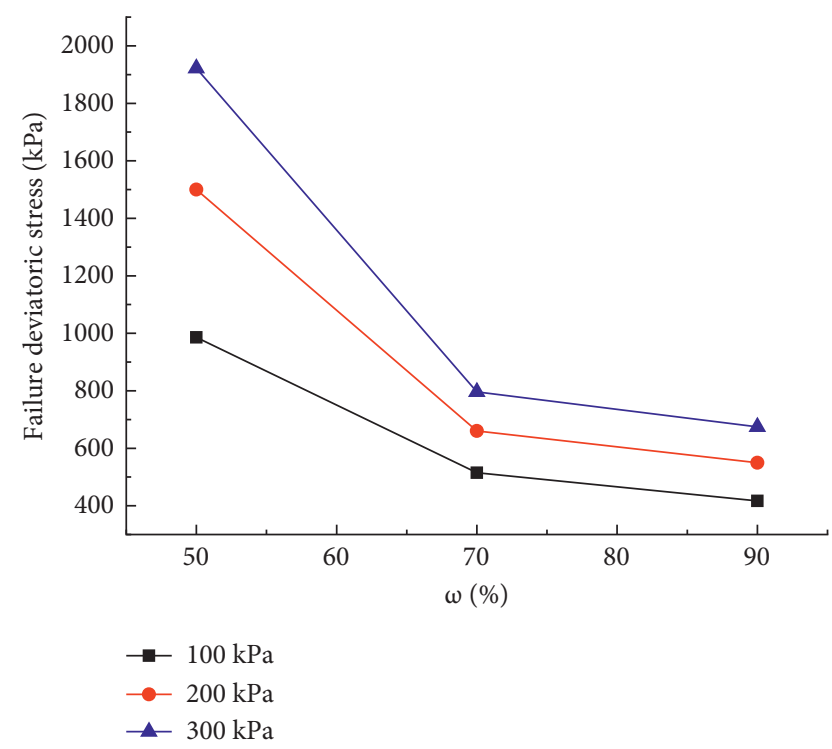

FIGURE 13: Relationship between failure deviatoric stress and water content.

Compared with the former condition, the decreasing amplitude was significantly reduced. It shows that the increase of water content of silt will reduce the deformation resistance of the improved silt. Especially, when the water content rose from $50 \%$ to $70 \%$, the decrease was most obvious. The relationship curve between failure deviatoric stress and water content of improved silt is basically same under different confining pressures, which indicates the reliability of this law.

Taken together, the incorporation of steel slag will increase the failure deviatoric stress of silt, and the failure deviatoric stress of silt with low moisture content will increase at a higher rate with the incorporation of steel slag. Under the condition of the same steel slag incorporation, the increase of water content will reduce the failure deviatoric stress of soil, but the reduction range will decrease continuously. The deviatoric stress of marine silt modified by steel slag increases proportionally with the increase of confining pressure under the same condition.

\section{The Shear Strength Index of the Sample}

According to the shear strength envelope of the sample, the cohesion and internal friction angle of the improved silt were obtained, as shown in Table 6.

In addition, the cohesive force and internal friction angle of the improved silt with $60 \%$ moisture content under steel slag incorporation $\alpha_{\mathrm{s}} 70 \%, 90 \%$, and $110 \%$ were supplementary measured, as shown in Table 7.

The relation curve between the internal friction angle of the cohesion force of the sample and the steel slag incorporation from Tables 6 and 7 is plotted in Figures 14 and 15.

4.1. Influence of Steel Slag Incorporation on Strength Index. As can be seen from Figures 14 and 15, the cohesion and internal friction angle of the improved silt increase under $50 \%$ moisture content with the continuous addition of steel slag. Among them, the increase of cohesion was larger. The increase of cohesion with the steel slag incorporation was greater when the steel slag incorporation ratio $\alpha_{s}$ was $\geq 50 \%$. Specifically, when $\alpha_{s}$ increases from $50 \%$ to $60 \%$, the cohesive strength changes from $85.17 \mathrm{kPa}$ to $95.52 \mathrm{kPa}$, increasing $10.35 \mathrm{kPa}$ and a growth of $12.2 \%$; when $\alpha_{s}$ increased from $60 \%$ to $70 \%$, the cohesive strength changed from $95.52 \mathrm{kPa}$ to $111.31 \mathrm{kPa}$, increasing $15.79 \mathrm{kPa}$ and a growth of $16.5 \%$. When $\alpha_{s}$ was $\geq 40 \%$, the internal friction angle of silt had an obvious upward trend with the increase of steel slag incorporation; when $\alpha_{s}$ increased from $40 \%$ to $50 \%$, the internal friction angle increased from $32.88^{\circ}$ to $38.68^{\circ}$, increasing $17.6 \%$; when increasing from $50 \%$ to $60 \%$, the internal friction angle increased by $10 \%$ from $38.68^{\circ}$ to $42.57^{\circ}$. It shows that the increase was continuously decreasing. In general, the addition of steel slag in the silt with $50 \%$ moisture content will increase the shear strength of the soil. Especially, when $\alpha_{s}$ is greater than $50 \%$, the cohesive strength of the soil increases obviously as well as the growth rate. When $\alpha_{s}$ is greater than $40 \%$, the internal friction angle of soil increases obviously but the increasing rate continuously decreases.

In the silt with water content of $70 \%$ and $90 \%$, the cohesion continuously decreases and the internal friction angle continuously increases with the continuous mixing of steel slag into the soil. When the steel slag incorporation $\alpha_{s}$ increased from $70 \%$ to $90 \%$, the increase of the internal friction angle was the most obvious. The internal friction angle of $70 \%$ and $90 \%$ moisture content increased from $23.37^{\circ}$ and $23.09^{\circ}$ to $44.55^{\circ}$ and $43.39^{\circ}$, respectively, with an increase of $90.6 \%$ and $87.9 \%$.

In the silt with $60 \%$ moisture content, the cohesion of the mixture tended to increase first and then decrease with the 
TABLE 6: Cohesion and internal friction angle of mixture soil.

\begin{tabular}{|c|c|c|c|c|c|c|}
\hline $\begin{array}{l}\text { Working } \\
\text { condition }\end{array}$ & $\begin{array}{c}\text { Moisture content } \omega \\
(\%)\end{array}$ & $\begin{array}{c}\text { Steel slag incorporation } \alpha_{s} \\
(\%)\end{array}$ & $\begin{array}{c}\text { Force of cohesion } C \\
(\mathrm{kPa})\end{array}$ & $\begin{array}{c}\text { Angle of internal friction } \\
\varphi\left(\left(^{\circ}\right)\right.\end{array}$ & $\begin{array}{c}\Delta C \\
(\mathrm{kPa})\end{array}$ & $\Delta \varphi\left(^{\circ}\right)$ \\
\hline MS-CSS11 & 50 & 30 & 76.09 & 33.52 & - & - \\
\hline MS-CSS12 & 50 & 40 & 83.18 & 32.88 & 7.09 & -0.64 \\
\hline MS-CSS13 & 50 & 50 & 85.17 & 38.68 & 1.99 & 5.8 \\
\hline MS-CSS14 & 50 & 60 & 95.52 & 42.57 & 10.35 & 3.89 \\
\hline MS-CSS15 & 50 & 70 & 111.31 & 44.51 & 15.70 & 1.94 \\
\hline MS-CSS21 & 70 & 70 & 121.29 & 24.37 & - & - \\
\hline MS-CSS22 & 70 & 90 & 78.04 & 44.55 & -43.25 & 20.18 \\
\hline MS-CSS23 & 70 & 110 & 63.6 & 49.6 & -14.44 & 5.05 \\
\hline MS-CSS31 & 90 & 70 & 95.49 & 23.09 & - & - \\
\hline MS-CSS32 & 90 & 90 & 72.69 & 43.39 & -22.8 & 20.3 \\
\hline MS-CSS33 & 90 & 110 & 61.2 & 50.83 & -11.49 & 7.44 \\
\hline
\end{tabular}

TABLE 7: Cohesion and internal friction angle of mixture soil with $60 \%$ moisture.

\begin{tabular}{|c|c|c|c|c|c|c|}
\hline $\begin{array}{l}\text { Working } \\
\text { condition } \\
\end{array}$ & $\begin{array}{c}\text { Moisture content } \omega \\
(\%)\end{array}$ & $\begin{array}{c}\text { Steel slag incorporation } \alpha_{s} \\
(\%)\end{array}$ & $\begin{array}{c}\text { Force of cohesion } C \\
(\mathrm{kPa})\end{array}$ & $\begin{array}{c}\text { Angle of internal friction } \\
\varphi\left(\left(^{\circ}\right)\right.\end{array}$ & $\begin{array}{c}\Delta C \\
(\mathrm{kPa}) \\
\end{array}$ & $\begin{array}{c}\Delta \varphi \\
\left({ }^{\circ}\right)\end{array}$ \\
\hline MS-CSS41 & 60 & 70 & 86.53 & 13.65 & - & - \\
\hline MS-CSS42 & 60 & 90 & 117.93 & 22.18 & 31.4 & 8.53 \\
\hline MS-CSS43 & 60 & 110 & 97.08 & 28.78 & -20.85 & 6.6 \\
\hline
\end{tabular}

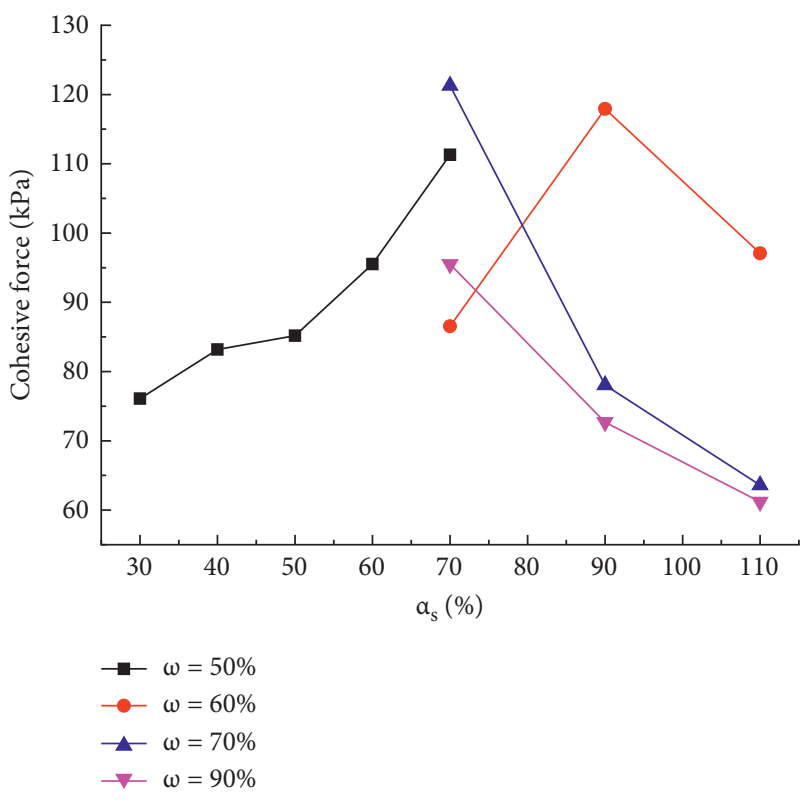

FIgURE 14: Curve of cohesive force of the mixture.

increase of steel slag incorporation. Compared with the continuous increase of cohesive force in the silt with $50 \%$ moisture content and the continuous decrease of cohesive force in the silt with $90 \%$ moisture content, the cohesive force of the steel slag-silt mixture with $60 \%$ moisture content just formed a transition. It further indicates that adding steel slag into the silt with lower water content (i.e., $\omega \leq 50 \%$ ) can enhance the cohesion of the improved silt. However, adding steel slag into the silt with higher moisture content (i.e., $\omega \geq 70 \%$ ) decreases the basic trend. It is found that the internal friction angle of the mixture increases with the increase of the steel slag incorporation of silt in different moisture content in the comparison of the internal friction

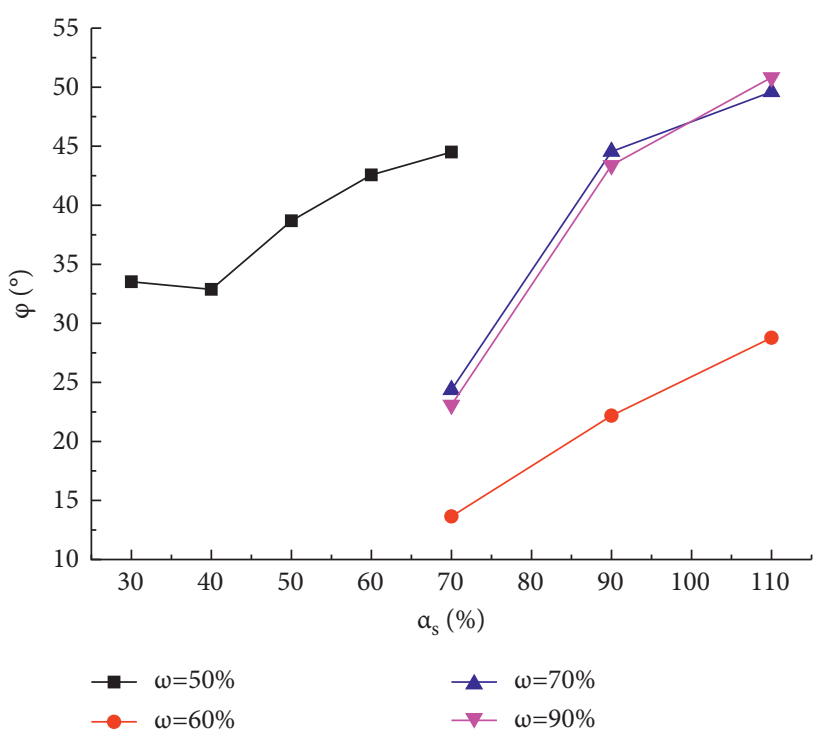

FIgURE 15: Curve of the internal friction angle of the mixture.

angle. It shows that adding steel slag into the silt with different water content can increase the internal friction angle of the improved silt.

Two basic functions of water in soil are introduced here to explain this rule: adhesion and lubrication. When the water content in the improved silt is high, large aggregates will be formed between the particles due to the action of water film, leading the correlation between the soil particles to get reduced. Water in the sample mainly plays a lubrication role at this time, and the values of $C$ and $\varphi$ of the improved silt decrease accordingly. The bonding effect of water begins to manifest when the water content in the improved silt reaches a certain amount, resulting in the cohesiveness between particles get enhanced, as well as the cohesiveness $c$ and internal friction angle $\varphi$ of the meliorated silt. It can be seen 
TABLE 8: Shear strength parameters.

\begin{tabular}{|c|c|c|c|c|c|}
\hline Soil group & Moisture content & Steel slag incorporation ratio $\alpha_{s}(\%)$ & $\begin{array}{l}\text { Density } \\
\left(\mathrm{g} / \mathrm{cm}^{3}\right)\end{array}$ & Cohesive force $c(\mathrm{kPa})$ & $\begin{array}{c}\text { Internal friction angle } \\
\left(\varphi\left({ }^{\circ}\right)\right)\end{array}$ \\
\hline \multirow{17}{*}{ Steel slag-silt mixture } & \multirow{6}{*}{$50 \%$} & $\alpha_{\mathrm{s}}=30 \%$ & 1.52 & 76.09 & 33.52 \\
\hline & & $\alpha_{\mathrm{s}}=40 \%$ & 1.51 & 83.18 & 32.88 \\
\hline & & $\alpha_{\mathrm{s}}=50 \%$ & 1.47 & 85.17 & 38.68 \\
\hline & & $\alpha_{\mathrm{s}}=60 \%$ & 1.43 & 92.52 & 42.57 \\
\hline & & $\alpha_{\mathrm{s}}=70 \%$ & 1.45 & 111.31 & 44.51 \\
\hline & & & & 86.53 & 13.65 \\
\hline & \multirow{5}{*}{$60 \%$} & $\alpha_{\mathrm{s}}=70 \%$ & - & 117.93 & 22.18 \\
\hline & & & & 97.08 & 28.78 \\
\hline & & $\alpha_{\mathrm{s}}=90 \%$ & - & 117.93 & 2218 \\
\hline & & $\alpha_{\mathrm{s}}=90 \%$ & - & 97.08 & 22.18 \\
\hline & & $\alpha_{\mathrm{s}}=110 \%$ & - & 97.08 & 28.78 \\
\hline & \multirow{3}{*}{$70 \%$} & $\alpha_{\mathrm{s}}=70 \%$ & 1.57 & 121.29 & 24.37 \\
\hline & & $\alpha_{\mathrm{s}}=90 \%$ & 1.51 & 78.04 & 44.55 \\
\hline & & $\alpha_{\mathrm{s}}=110 \%$ & 1.46 & 63.6 & 49.6 \\
\hline & \multirow{3}{*}{$90 \%$} & $\alpha_{\mathrm{s}}=70 \%$ & 1.73 & 95.49 & 23.09 \\
\hline & & $\alpha_{\mathrm{s}}=90 \%$ & 1.57 & 72.69 & 43.39 \\
\hline & & $\alpha_{\mathrm{s}}=110 \%$ & 1.53 & 61.20 & 50.83 \\
\hline Steel slag & - & - & 1.94 & 5 & 39 \\
\hline Silt soil & - & - & 1.62 & $1-8$ & $1.5-10$ \\
\hline Clay & - & - & $1.75-2.1$ & $22-40$ & $5-15$ \\
\hline Silty clay & - & - & $1.95-2.1$ & $5-10$ & $27-30$ \\
\hline Sand clay & - & - & $1.95-2.1$ & $6-12$ & $23-25$ \\
\hline Coarse sand & - & - & $1.9-2.05$ & $0-2$ & $38-42$ \\
\hline Medium sand & - & - & $1.9-2.05$ & $1-3$ & $35-40$ \\
\hline Fine sand & - & - & $1.9-2.05$ & $2-6$ & $32-38$ \\
\hline Mealy sand & - & - & $1.9-2.05$ & $6-8$ & $34-36$ \\
\hline Loess (remolded) & - & - & $1.4-1.9$ & 50 & 22.25 \\
\hline
\end{tabular}

that when $30 \%$ to $70 \%$ steel slag was mixed into the silt with $50 \%$ moisture content, the bond between the silt was the main due to the moderate moisture content. The water content further decreases with the increase of steel slag incorporation, leading to the bond between particles get strengthened, as well as the cohesive force increased. When the silt moisture content was $70 \%$ and $90 \%$, the water in the soil mainly acted as lubrication, and the excess water was not easy to be absorbed by the steel slag. Moreover, the addition of steel slag took up the bonding space of the original soil particles, which further reduced the bonding degree and cohesion of the soil. The friction between steel slag particles increased with the increase of steel slag incorporation during loading, resulting in the internal friction angle of the soil get increased.

Taken together, adding steel slag to the low moisture content silt will enhance the bond of the soil and thus the cohesion of the soil. It is not easy for the water to be fully absorbed when steel slag is added to the high moisture content silt, leading the original bond of the soil to be destroyed as well as the cohesion of the soil will be reduced. However, for silt with different water content, the friction between particles increases with the increase of steel slag incorporation as well as the internal friction angle of soil increases.

\section{Working Conditions of Application}

Through the previous experimental study, the shear strength index of the silt mixed with steel slag was compared with that of the traditional soil, as shown in Table 8. Column charts of cohesion and internal friction angle are drawn in Table 8, as shown in Figures 16 and 17, respectively. It can be seen from Table 7 that, compared with the traditional improved silt, the silt improved by steel slag has higher cohesion and internal friction angle. The results show that the modified silt with steel slag particles has the advantages of shear strength that traditional soil does not have, and the shear strength of the modified silt will continue to increase with the increase of steel slag particles.

As can be seen from Figure 16, the cohesive force of improved silt with different water content is higher than that of traditional clay and sand. The cohesion of traditional clay is between 8 and $40 \mathrm{kPa}$, and the cohesion of traditional sand is between 0 and $10 \mathrm{kPa}$. However, the cohesion of silt modified by steel slag is about $60 \sim 120 \mathrm{kPa}$, which is obviously higher than that of traditional clay and sand. In addition, the cohesiveness of both pure silt and steel slag in the figure is below $10 \mathrm{kPa}$, while the cohesiveness is greatly improved when the silt is mixed with steel slag. It shows that the strength of steel slag and silt, two kinds of low cohesive materials, is greatly improved after mixing, which further enhances the reliability of its application in engineering construction.

As can be seen from Figure 17, the internal friction angle of traditional sand is about $35^{\circ}$ to $45^{\circ}$, which is higher than that of traditional clay $\left(5^{\circ}\right.$ to $\left.30^{\circ}\right)$. The internal friction angle of traditional silt is small between 0 and $10 \mathrm{kPa}$. While the variation of the internal friction angle of silt modified by steel slag is similar to that of sandy soil in the range of $25^{\circ}$ and 


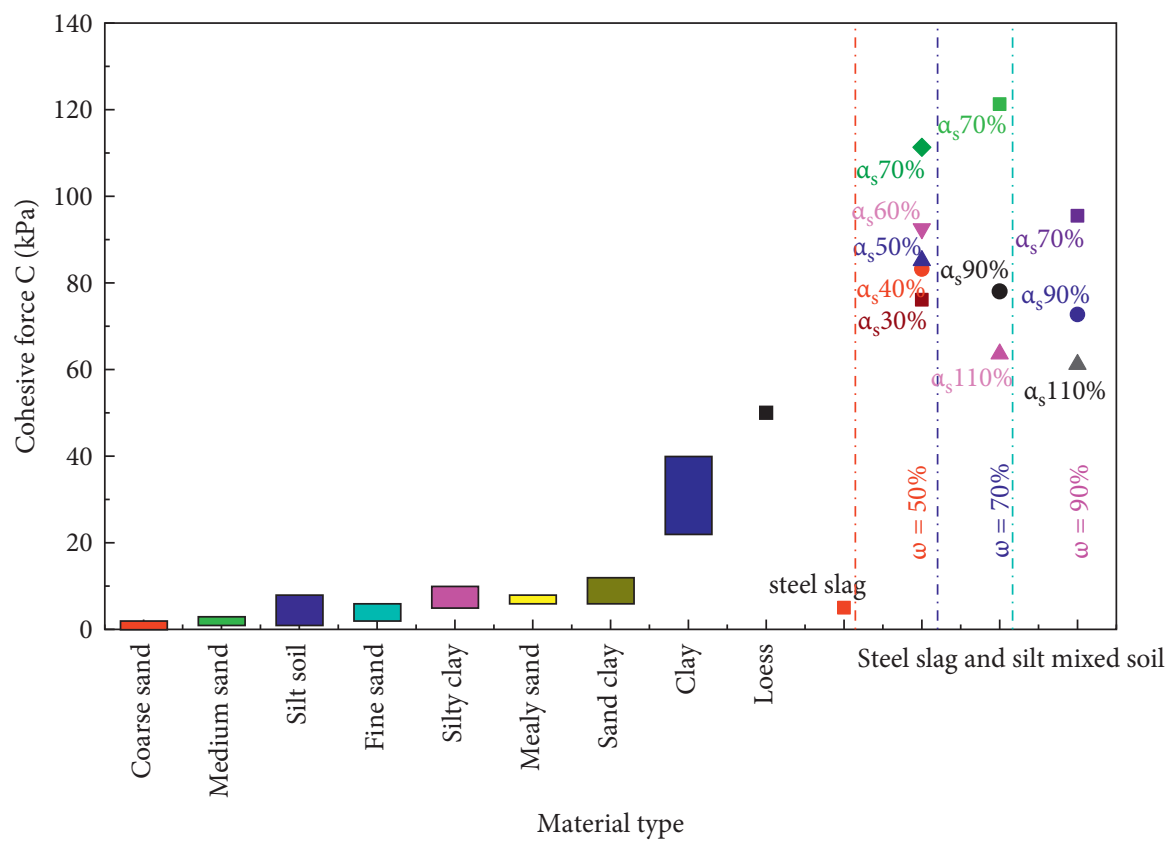

FIgURE 16: Cohesive force of mixture and different traditional soil.

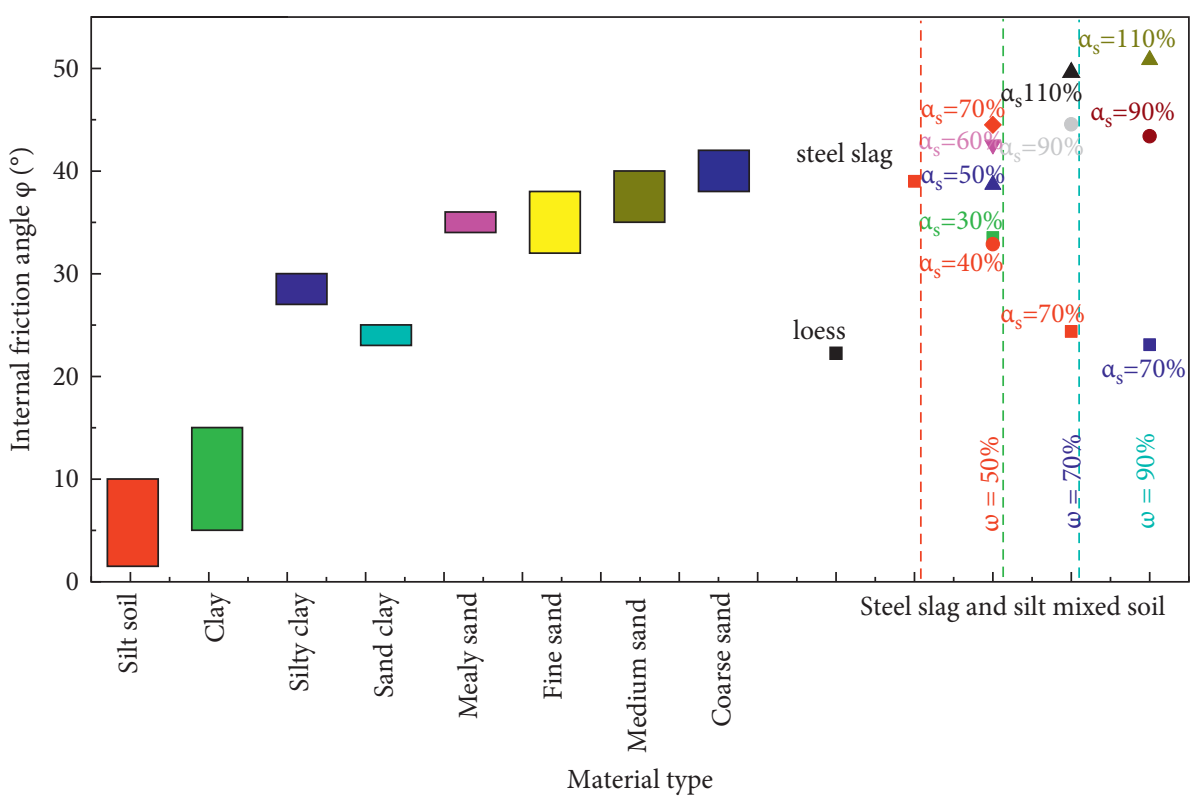

Figure 17: Internal friction angle of mixture and traditional soil.

$50^{\circ}$, it is significantly higher than that of traditional silt. It shows that the variation of the internal friction angle of improved silt is similar to that of sand soil, which is suitable for engineering construction.

\section{Conclusions}

In this paper, the static strength characteristics of silt under different water content and steel slag incorporation are analyzed from the angle of stress-strain curve characteristics, failure deviatoric stress, cohesion, and internal friction angle. Compared with the traditional improved silt, it is concluded that the cohesion and internal friction angle of the soil are significantly improved by adding steel slag into the silt, and the improvement of cohesion is more obvious. It indicates that mixing steel slag and silt can significantly improve the strength characteristics of soil and facilitate its application in engineering construction. The specific conclusions are as follows:

(1) Under the same compaction condition, the density of silt modified by steel slag soil increases with the increase of the steel slag incorporation, but the growth rate continuously reduced. The density of the sample tended to be stable eventually due to the influence of the compaction degree of the steel slag. 
(2) The stress-strain curves of marine silt modified by steel slag are all strain hardening type. In the 50\% moisture content and steel slag incorporation $\alpha_{s} \geq 50 \%$ silt and in the $70 \%$ and $90 \%$ moisture content and steel slag incorporation $\alpha_{s} \geq 90 \%$ silt, the linear characteristics of the stress-strain curve of the sample are both obvious as well as the structure of the sample is strong.

(3) In the triaxial test, the failure mode of the sample was the same as that of the traditional soft clay, both of which were drum failure with small in the middle and big on the sides. The confining pressure had little effect on the stress-strain curves of the samples, and the stress amplitude of the samples increased clearly with the confining pressure.

(4) The addition of steel slag increased the failure deviatoric stress of the silt. After the addition of steel slag, the amplitude of the failure deviatoric stress of the soil with low moisture content increased greatly, and the rate of increase was quicker, and the soil had a greater ability to resist deformation and failure. The soil had the characteristics of compressive rigidity, and the increase of failure deviatoric stress was almost proportional to the increase of confining pressure.

(5) The increase of water content would reduce the antideformation and failure ability of silt modified by steel slag soil. Especially, the water content rose from $50 \%$ to $70 \%$, and the decrease was most obvious.

(6) In the water content of $50 \%$ silt modified by steel slag soil, the soil cohesive force increased with the increase of steel slag incorporation. However, in the silt modified by steel slag soil with the water content of $70 \%$ and $90 \%$, the soil cohesive force decreased with the increase of steel slag incorporation.

(7) The internal friction angle of the steel slag modified silt modified by steel slag with different water content increased with the increase of steel slag incorporation, but the growth rate of the internal friction angle decreased.

(8) Compared with the traditional soil, the silt with a moisture content of $50 \%$ mixed with $70 \%$ steel slag had higher shear strength. In the silt with water content of $70 \%$ and $90 \%$, the cohesion of the improved silt was the best when the steel slag incorporation was $70 \%$. The internal friction angle of the improved silt was the largest as steel slag was added at $110 \%$.

\section{Data Availability}

The data used to support the findings of this study are available from the corresponding author upon request.

\section{Conflicts of Interest}

The authors declare that they have no conflicts of interest.

\section{Acknowledgments}

This research was financially supported by the Natural Science Foundation of Jiangsu Province (Grant No. BK20201454), the National Natural Science Foundation of China (Grant no. 51978317), Key Laboratory of Ministry of Education for Geomechanics and Embankment Engineering, Hohai University (Grant No. 2020013).

\section{References}

[1] J. Guan, J. Zhang, and Z. Shangguan, "Experimental study of the mechanical parameter of marine ooze soil," Value Engineering, vol. 32, no. 24, pp. 86-88, 2013.

[2] S. Cui, The Laboratory Test of CFS Pile Material and Simulation Study of Its Composite Foundation, China University of Geosciences, Beijing, China, 2015.

[3] D. Deng, T. Zhang, and S. Zhang, "Technique for utilization of high-water-content dredged clayey soil as fill material for the eastern route of south-to-north water diversion project," Journal of Hohai University (Natural Sciences), vol. 4, no. 36, pp. 34-36, 2008.

[4] T. Zhang, J. Ding, and D.-s. Deng, "Change law of water content of dredged clays treated by quick lime," Rock and Soil Mechanics, vol. 9, no. 30, pp. 2775-2778, 2009.

[5] W. Cai, "Effect of fly ash on physical and mechanical properties of solidified sludge," China Science and Technology Information, vol. 21, no. 8, pp. 43-49, 2012.

[6] G. Xie, H. Du, and S. Zhu, "Experimental study of solidification of dredged silt with novel ash-slag based cementious materials," Solid Waste Utilization, vol. 1, pp. 26-28, 2011.

[7] Y.-n. Shi, J. Yu, J. Zhou, and C. Zhang, "Indoor experiment on curing of dredged soil," Port and Waterway Engineering, vol. 491, no. 5, pp. 133-138, 2014.

[8] F. Chen, X. Lei, and Q. Meng, "Experimental study on the mechanical properties of solidified dredging silt of high moisture content," Science Technology and Engineering, vol. 15, no. 1, pp. 295-298, 2015.

[9] P. Chen, Y. Gao, and M. Gao, "Experimental study on solidification method for dredged mud mixed with MSWI," Journal of Hydraulic Engineering, vol. 46, no. 6, pp. 749-756, 2015.

[10] Y. Peng, J. Yang, and X. Chen, "Study on the mechanism and strength of compound stabilized saline dredged sludge by industrial waste," Journal of Zhejiang Institute of Communications, vol. 17, no. 3, pp. 25-29, 2016.

[11] L. Wang, P. Gao, R. Xue, and X. Wang, "Experimental study on deformation behavior of mixed light-weight sand soil with steel slag," Subgrade Engineering, no. 3, pp. 15-20, 2013.

[12] W. Li, H. Wang, F. Li, X. Zhang, and W. Song, "Test study on the mechanical characteristics of soil mixed with steel slag and sand," Journal of Shenyang Jianzhu University (Natural Science), no. 5, pp. 794-799, 2008.

[13] S. Sun, J. Tang, Q. Zheng, G. Zhang, L. Zhou, and W. Shang, "Experimental study of expansive soil improved with granulated blast furnace slag (GBFS)," Rock and Soil Mechanics, vol. 33, no. 7, pp. 1940-1944, 2012.

[14] L. Wang, R. Fu, and L. Hu, "Experimental study on compressive strength properties of cement soil blended with steel slag," Construction Technology, vol. 43, no. 17, pp. 97-122, 2014.

[15] I. Z. Yildirim and M. Prezzi, "Geotechnical properties of fresh and aged basic oxygen furnace steel slag," Journal of Materials in Civil Engineering, vol. 27, no. 12, Article ID 04015046, 2015. 